\title{
ON THE CURE
}

\section{or \\ R A M O L L I S E M E N T \\ OF THE BRAIN.}

By JOHN SIMS, M.D.,

PHYSICIAN TO THE ST. MARY-LE-BONE INFIRMARY.

READ 9TH JUNE, 1835.

Two varieties are principally observed on dissection, in the early stages of ramollissement of the brain: one, of a red colour, chiefly taking place in the gray matter covering the convolutions, or in that of the corpora striata, \&c., and not unfrequently in the white matter, when connected with apoplectic extravasation of blood; the other, of a white colour, or sometimes of a pale yellow colour, occupying the white matter of the brain. This frequently occurs in the central parts of the brain of children, and of adults who die of the inflammatory disease termed hydrocephalus acutus ; it is also frequently met with in the brains of old people connected with diseased blood-vessels, and other morbid appearances, and is then most probably not an inflammatory affection. 
The colour of the red ramollissement appears to arise from the capillary vessels, carrying red blood, being dilated in the softened spots, from extravasation, or from transudation through the coats of the vessels, or probably from all these circumstances taken together.

The colour of the white ramollissement is probably occasioned by the softening taking place in the intensely white part where no red capillaries are seen, as the corpus callosum and the fornix, or in the white matter where red vessels are seen. sparingly, it may take place in small medullary patches, at a little distance from these vessels, so as not to endanger their laceration; or in cases of diseased arteries, the red vessels in patches of the white matter have become ossified, cartilaginous, or obliterated; or the colour may be influenced by the admixture of lymph or puriform fluid with the softened parts of the white matter.

In examining the brains of persons who have in a former period suffered apoplexy, paralysis, vertigo, loss of feeling or motion; we find generally some or other of the following appearances: cicatrices; cysts, containing less or more fluid; also an ochre or fawncoloured matter, the evidence of former extravasation; small holes of various sizes, lined by a thin, transparent membrane, and containing serous fluid; atrophy of the gray and white matter; small spherical lumps of coagulated blood; serous fluid in the membranes, the ventricles, and the substance of the brain. 
I am inclined to believe the atrophy of the gray matter, whether on the surface or in the central parts of the brain, when a fawn-coloured deposit is connected with the wasted spots, and the numerous small holes in the white matter with yellow deposit, as evidence of the arrest or cure of red ramollissement : and the clean cut cavities in the white matter, and sometimes in the gray matter attached to it, and very often in the gray matter of the corpora striata ; the numerous small holes lined by a pale membrane, vascular or not, and containing serous fluid; also the newbread, or porous cheese appearance, and the small, harder lumps in the white matter, and the general hardening of it, as evidence of the arrest or cure of white ramollissement. In the following pages I shall endeavour to illustrate, and I trust to prove, the truth of this position, by several dissections of the brains of persons in whom these appearances were found.

Most of the authors who have written on the pathology of the brain are silent on the subject of the cure of ramollissement; some deny that it ever takès place, and others again have explained some of the phenomena, and very recently Cruveilhier has advanced still further in this inquiry.

M. Lallemand *, at the close of his second letter, relates the dissections of two cases in which he found

* Récherches Anat. Path. sur l'Eucephale, \&c. Let. II. p. 305. 
traces of the cure of ramollissement, the patients having had signs of this affection which had disappeared. The first a girl, ret. 14, in which a portion of the white matter of one hemisphere was hardened, and presented the appearance of "fromage de gruyere." In the other case, a man æt. 55, there was adhesion between the dura mater, the arachnoid, and the surface of the convolutions, the gray matter being hardened like cartilage or scirrhus.

M. Andral states, that out of 105 persons affected with ramollissement, upwards of sixteen survived the first month, more than ten the second month, seven survived the third month, and two lived for three years. $\mathrm{He}$ is almost decided in the opinion, that the disease is uniformly fatal ; and then asks the question, "can ramollissement be cured ?" He supposes that, in order to answer the question in the affirmative, it is necessary exactly to determine the precise symptoms which distinguish ramollissement from other diseases of the brain, which has not yet been done. Now this mode of reasoning appears to me to be begging the question, and to have nothing to do with the argument; for if we can, by repeated dissections, trace the steps by which nature appears to cure this disease, it is of little moment whether our notions respecting symptoms correspond with these phenomena or not; or in other words, if we can settle the anatomy of the question, we shall be in a moie competent state to estimate the value of, or to appropriate the symptoms we observe during life. He 
approves of Rostan's declining, from the want of diagnostic symptoms, to give an opinion on this question, and thinks that M. Lallemand has not satisfactorily shewn, that circumscribed induration is any proof of the cure of ramollissement*.

In the article "Aliénation Mentale," in the Dictionnaire de Médecine et de Chirurgie Pratique, M. Foville relates, that in the brains of lunatics he found, on the surface of the convolutions, numerous linear depressions and irregular pittings, leaving in the intervals eminences of different sizes; also many small yellowish lacunæ filled with serous fluid; these last he considers to arise from numerous small extravasations of bloodt. He proceeds to observe, that he

* “ Jusqu'à présent nous avons toujours supposé que le ramollissement des hémisphères cérébraux se terminait d'une manière fatale. Peut-il cependant se terminer d'une manière heureuse ? - . . Ce sont des faits de cette nature qui déjà avaient engagé M. Rostan, à ne pas se prononcer sur la question, de savoir si le cerveau, une fois privé da sa consistance normale, peut la recouvrer. Cette reserve nous parait commandée par l'etat actuel de la science, et nous ne croyons pas que M. Lallemand ait suffisamment démontré, par les cas qu'il à cités, que l'induration circonscrite d'un des hémisphères est quelquefois - l'indice d'un ramollissement qui a guéri. Ce sont-là de belles recherches à poursuivre, mais qui ne pouront conduire a quelque résultat qu'à la condition que l'on s'efforcera d'abord de perfectionner de plus en plus le diagnostic du ramollissement du cerveau." Clinique Med., Vol. V., p. 589.

+ “ Ce sont quelquefois des dépressions linéaires, des enfoncemens irreguliers qui laissent dans leur intervalles des bosselures de differens volumes. Il n'est pas rare, dans les cas où

vOL. XIX.

C C 
has four or five times met with circular patches from half an inch to an inch, in which there was a complete absence of the gray matter with defined edges, and with a clean, white, and firm base, and lined by a transparent cellular membrane; this alteration he considers as the consequence of ramollissement*. He mentions another state of the brain, which he says is more rare, and which M. Esquirol had already noticed, in which there is a multitude of small cavities, from the size of a millet-seed or hemp-seed to that of a nut, containing a clear fluid with clean and white walls, resembling in some degree a porous cheese: in these holes he has not been able to discover a lining membrane. He then puts the question, whether these cavities have succeeded numerous bloody extravasations? This he thinks possible, but admits that he has never been able to find in

la surface des circonvolutions est ainsi bosselée, de trouver dans l'epaisseur de la substance corticale une multitude de petites lacunes jaunâtres remplies d'une sérosité de même couleur; il est bien probable que ces petites lacunes ont succeedé aux epanchemens sanguins miliaires que nous avons signalés en parlant des alterations aiguies." p. 637.

* "Je crois qu'il faut considerer comme suite de ramollissemens partiels de cette espece un alteration que j'ai rencontré quatre ou cinq fois, et qui consiste dans l'absence complète de la substance grise dans une etendue circulaire variable de la grandeur d'un demi-pouce à un pouce. Les bords de cette perte de substance sont taillés presqu'a pic; le fond en est lisse, blanc, ferme, et ne semble pas autre chose que la portion fibreuse de la circonvolution. La membrane celluleuse qui la tapisse est aussi transparente, aussi fine que celles des ventricules." p. $\mathbf{5 4 0 .}$ 
them the yellow rusty colour which even ancient apoplectic cysts so often present*.

I hope in the sequel to make it appear that most if not all these appearances are to be considered as traces of the process employed by nature in arresting or curing white or red ramollissement.

Dr. Carswell states that blood effused into the brain may be absorbed and the wound cicatrized, and that softened cerebral substance may also be absorbed; but he says, "we have never seen a case in which its removal was followed by cicatrization." He goes on to say, "the first change which indicates the removal of the softened cerebral substance is the formation of an excavation, containing a milky,

* “ Une autre alteration plus rare, que M. Esquirol a déjà remarquée, est la presence dans le cerveau d'une multitude de petites cavités capables de loger un grain de millet, de chénevis, quelquefois même une noisette.

“ Dans tous les cas de cette espèce que jai rencontré, le liquide contenu était aussi limpide que de l'eau, et les parois de ces petites cavités parfaitement lisses et blanches.

“ Une section pratiquée dans un cerveau ainsi altérê, presenté une grande resemblance avec l'aspect de certaines fromages. Je n'ai pu parvenir a separer de ces cavités une membrane distincte, quoiqu'on en puisse raisonnablement supposer l'exist. ence.

"Ces petites cavités, ces petites collections sereuses, ont elles succédé à de nombreuses epanchemens sanguins? Cela est possible; mais jamais elles ne m'ont offert cette couleur jaunâtre, rouille clair, que des kystes apoplectiques, même anciens, offrent si souvent." p. 544. 
grayish, reddish, or yellowish fluid matter, with sometimes a small quantity of loose, cellular tissue. By and bye this matter becomes fluid and limpid, and the cellular tissue is found transformed into a serous membrane which lines the surface of the excavation." Dr. C. has met with three cases, and they occurred in persons under forty years of age: the cases are so slightly alluded to, that it is difficult properly to appreciate their character*.

M. Cruveilhier, in the number of his "Anatomie Pathologique" just published, has investigated the subject of the cure of ramollissement more satisfactorily than any preceding writer. He relates several instances of the yellow discoloration of the convolutions connected with irregular depression and loss of substance in the gray matter. The various shades of yellow discoloration, he thinks, are the indelible marks of previous extravasation from capillary apoplexy. After describing the several forms of softening, he observes, "On peut guérir d'un ramollissement. Mais un ramollissement antérieurement épreuvé en amène presque toujours une second, un troisième. Comme la possibilité de la guérison des ramollissement de cerveau a été contestée, je crois devoir citer un fait bien positif à l'appui de cette proposition." +

* Cyclopedia of Practical Medicine, Article "Softening of Organs." p. 6.

+ Anatomie Pathologique, Maladies du Cerveau, No. XX., p. 9. This number was published in Paris, May lst, and copies appeared in London about ten days after. 
In his remarks on this case, he alludes to the loss of substance, with yellow cicatrices in the gray matter, and to the small pisiform holes, sometimes without discoloration, in the white matter, as traces of the cure of ramollissement*.

Instances of the cure of ramollissement are frequently to be met with in dissecting; I believe they have been described by pathologists as extraordinary excavations, ulceration, or traces of apoplectic extravasation of blood. Cases of this kind might, probably, be taken indiscriminately from any author of

* “ Le mode de cicatrization de la substance blanche ramollie consiste quelquefois dans de la cellulosité infiltrée d'une bouillie claire à la manière du lait de chaux; que le mode de cicatrization de la substance grise ramollie consiste dans des pertes de substance avec cicatrice jaunâtre."

“ Il me parait probable que les cicatrices des circonvolutions, si frequentes chez les viellards, que les petits foyers pisiformes presque toujours sans coloration manifeste que l'on rencontre si souvent au milieu de la substance blanche, sont la suite du ramollissement du cerveau nous voyons souvent à la Salpêtrière; des femmes qui eprouvent de tems a autre des etourdissemens, la perte momentanée de la parole, un engourdissement temporaire de telle ou telle partie du corps, dont les facultés s'affaiblissent à châque attaque, jusqu'à ce qu'enfin elles tombent dans l'idiotie, et qui finissent par succomber à un ramollissement considerable ou à une attaque d'apoplexie: on trouve à l'ouverture une multitude de cicatrices ou cicatricules avec perte de substance des circonvolutions avec coloration jaunâtre, brun-jaunâtre, peau de chamois, dont chacune repond probablement à une petite attaque, laquelle ne serait autre chose qu'un ramollissement très circonscrit." P. 10. 
acknowledged reputation on the pathology of the brain.

Case 121*, in Dr. Bright's work, I take to be one of ramollissement cured, and Case 145†, to be one of ramollissement in the progress of cure, and not apoplectic extravasation.

- "Medieal Reports : Diseases of the Brain. Hemiplegia, connected with serous effusion into the ventricles, and a superficial excavation on one of the convolutions."

"Sectio-And on the left hemisphere, close to the temple, one of the convolutions was excavated to the extent and depth of half a hazel nut; it looked clean, and more like a cavity which had contained purulent fluid than like a recent ulcer. Eleven ounces of fluid in the cavities."

"Remarks-It is not quite evident to what canse we are to ascribe excavations of this kind; not improbably they are the results of laceration and injury of the brain, followed by absorption of the injured parts." Page 253.

+ "Hemiplegia on the left side, with cerebral injury on the same side."

"Sectio-Membranes stripped easily from convolutions, except on the lateral and outer part of left hemisphere; to which they were glued by a thin, opake, yellow flake of deposit, like fibrine. Immediately below this adhesion, and extending to the middle of the corpus striatum, was an opaque portion of brain, considerably harder than the brain itself; plainly shewing in its centre that it was the scar of an apoplectic cyst, surrounded by hardened parietes. The cavity was scarcely so large as a French bean, containing a little softened curd-like substance. The derangement from the injury evidently extended from the middle of the corpus striatum to the surface of the middle lobe." Page 307. 
M. Scoutetten relates two cases which he describes as ulceration of the gray matter on the surface of the brain. He justly refers the symptoms to inflammation of the membranes, the one acute, the other chronic; and I think we may go a step further, and say that they were cases, not of ulceration, but of inflammatory ramollissement ; the first in the progress of cure, from the dry and hard state of the surface of the ulcer and the sound state of the brain beneath. Of the second case there can be no doubt, and the author appears very nearly arriving at the same opinion, when he asks, "Comment se fait-il que le tissu cérébral sous-jacent à l'ulcération offrant les caractères de ramollissement ?" \&c. This case appears not so far advanced, and the subject was of a bad constitution, and probably slow in setting up the restorative process*.

I shall proceed to relate several cases of ramollissement of the brain, in which I conceive traces of the arrest or cure of this disease are evident.

During the last two or three years, I have often pointed out the appearances in the brain which $I$ consider to be traces of the arrest or cure of ramollissement of the brain, in the presence of the medical officers of the Infirmary and other professional gentlemen. Mr. Hutchinson, of Welbeck Street, at the time he was House-Surgeon of the Infirmary, made

* Archives Générales de Medecine, Vol. VII., p. 31. 
several of the dissections of the brain, and took notes, at my request, of many of the cases contained in this and the two preceding papers.

\section{$C A S E \quad I$.}

Recent Ramollissement-rouge on the Surface; Traces of Ramollissement cured in the central Parts.

Mary Green, æt. 60, admitted with symptoms of gastro-enteritis, great tenderness of abdomen, and constant vomiting, which the remedies used did not relieve. She continued to decline until within two days of her death, when slight delirium came on, succeeded by coma. She appeared to have lost her sight, and during the last thirty-six hours she was pointing her fingers forwards, and appeared to be intently looking at them. She had been a patient in the Infirmary several months ago with diarrhœea, from which she was considerably relieved.

Inspection, May 9th, 1835, twenty-five hours after death.-Head. High congestion of the veins of the surface, which were beautifully tortuous. The blood-vessels of the brain were loaded throughout. In the cavity of the arachnoid there was extravasation, and coagulum on some parts of the brain, in small thin layers. It might appear doubtful whether this was a post-mortem appearance, or one which occurred in the last moments of existence; but it is highly probable that it was connected with some spots of red ramollissement which appeared on the inferior part of 
both posterior : lobes of the cerebrum. This was small in extent, and little more than a third or a half the depth of the gray matter, which was red from torn vessels and slight extravasation, so as to present the appearance of being worm-eaten. The arachnoid and pia mater adhered to the brain partially at these points. There was a fawn-coloured hole, the size of a pea, in the right thalamus. In the gray matter of the left corpus striatum there was a small cavity, with fawn-coloured lining, and around it were several small holes, without fawn-coloured deposit. There did not appear to be any holes in the medullary matter. Effusion of serous fluid in the sub-arachnoid tissue, of a gray colour. Four ounces of fluid in the ventricles, of old standing. Weight, 2 lbs. 4 oz.

Thorax. - Several cicatrices of old cavities in the upper part of the lungs, one, containing gritty matter, the size of a marble. Heart : globular hypertrophy, with contraction of left ventricle : dilatation of right auricle and ventricle.

Abdomen.-Stomach : a portion was of a very dark colour, the remains of chronic gastritis. . Liver : pale, surface contracted in places, and considerable deposit of cartilage. Small intestine : ulcerations, some of which were healed: small granules on the peritoneum. Kidneys: granular; small.

Remarks.-In this patient's brain there appear to be traces of ramollissement in different stages of 
cure. In the softened spots on the surface of the posterior lobes of the hemispheres, absorption had taken place, and adhesion between the pia mater, arachnoid, and brain. The several small holes without discoloration around the larger cavity, lined by a fawn-coloured membrane in the gray matter of the left corpus striatum, appear to me to attest the preexistence of a softened state of the brain surrounding an extravasated clot, and that these cavities are the traces of its arrest and cure.

\section{CASE II.}

Several attacks of Paralysis; Ramollissement; Holes in the Brain; spherical Lumps of coagulated Blood.

Mrs. A. S., æt. 50, has latterly suffered much from anxiety and fatigue, occasioned by severe domestic affliction.

Nov. 22d, 1831. Complains of a sensation of uneasiness in her head, not amounting to pain: head cool. She appears to have lost the control over the muscles of the voice, and cannot pronounce some letters, and most of her words are spoken thickly. She protrudes the tongue properly; she has no paralysis of the face, and her intellectual faculties appear entire. Tongue loaded. Pulse 100, sharp, and contracted. Catamenia have ceased about three months ago. 
On the 18th, when visiting one of her daughters, she mentioned to me a sensation, which she described as irritation or nervous uneasiness in her head, attended with floating specks, which had existed for some time, but had not forcibly attracted her attention. She exerted herself very much on that day, and on the following this affection of the tongue was first noticed.

Dec. 1. When all her family were from home, after fatiguing herself with dressing her hair, she was suddenly seized with great nervous excitement and alarm, and experienced a change of sensation in her left hand and a dragging of her left leg.

I saw her on the 2d. Her head was free from pain, but her mind exceedingly excited. She complains of things feeling hot and rough to the left hand, without loss of the power of moving it. On trying to walk, her left leg appears to slip to the right side, and she walks very feebly. Pulse quick, but rather feeble.

Her symptoms very soon improved; the sensation in her hand, and the power of moving her leg, gradually returned to nearly their natural state: her nervous agitation occasionally appeared, and at one time it bordered on incoherence.

On the 1st of April, 1832, she had another attack. I saw her on the $\mathbf{3 d}$, when her articulation was very 
indistinct; left eye protruding; left angle of the mouth drawn down; diminished power of moving the left upper extremity, particularly the fore-arm, with very feeble power of grasping; no loss of sensation in the limb; no impediment in walking. Pulse small, sharp, and quick; heart beat with much labour over a large surface:-(probable hypertrophy, with contracted cavity of left ventricle.) Her general manner is altered, and her understanding and feelings appear to have sustained a shock by this attack. She recovered from some of her symptoms, but the paralysis of the left arm remained.

During the succeeding eighteen months she suffered several attacks of more or less severity, and of a character similar to those $I$ have described; in one of which the left leg was again paralyzed, which was never recovered. Her understanding, which had been excellent, gradually became enfeebled, and her feelings, previously very acute and susceptible, were in some measure blunted: these circumstances were, however, such as could only be considered a slight approach to childishness. Her appetite and strength declined, and she was much reduced in flesh. She died in the beginning of 1834 .

Jan. 22. Inspection, the day after her death.Head. Skull hard, with a thick os frontis. The arachnoid and velum interpositum were opaque and of a light slate colour: there was some fluid between the membranes, and from four to six ounces in the ven- 
tricles. There was an old fawn-coloured deposit in the left hemisphere of the cerebrum: the thalamus of the right side was softened. The blood-vessels were thickened with white deposit. Many small holes were observed, appearing like worm-eaten cavities, in both hemispheres of the cerebrum; some were also found in the cerebellum; they were of various sizes, some spherical, and others of an irregular shape; some were quite clean, and not at all discoloured, especially in the white matter; others were lined by a light fawn-coloured membrane. Several small black spherical bodies were observed; much resembling melanotic matter, in two or three places : they were afterwards found to be portions of coagulated blood inclosed in a membrane; the surrounding white matter was not tinged by the blood. The substance of the cerebrum, with the exception of the right thalamus, was harder than usual.

Thorax.-Hypertrophy of left ventricle of the heart. Other viscera examined, natural.

Remarks.-From the symptoms detailed in the preceding history, we may observe, that the patient nearly recovered from the first paralytic seizure, when, at the end of four months, a second occurred, of a more severe character ;' and that some of the symptoms of this and the subsequent ones were par. tially removed. The various holes found in different parts of the cerebrum and cerebellum, the fluid ef: 
fused, and the hardening of the cerebrum, are traces of previous disease in the organ, which I take to have been ramollissement without extravasation, excepting in the holes where yellow matter was found. I think this is the more probable, if not amounting to proof, from the softened state of the right thalamus, the diseased part producing the increasing and permanent palsy of the left arm. The holes with yellow colouring are traces of extravasation, added to the softening. The thickened os frontis, the effused blood, the various cavities in the brain, appear to me to be connected with the decay of intellect and the obtuseness of feeling observed in a person previously remarkable for intelligence and sensibility.

I am at a loss to account for the small spherical portions of coagulated blood, unless the following be a satisfactory solution. They were lined by a fine membrane, and the surrounding portion of brain was untinged and apparently uninjured. It is probable, that portions of the brain being softened, admitted of the dilatation of some of the blood-vessels, and a deposit of blood in the form of the coagulum of an aneurism; that the membrane lining the cavity in which these spherical coagula were found was the coats of the blood-vessel ; and that, consequently, the substance of the brain was not injured by laceration, as in ordinary extravasation. It is also not improbable that some of the smaller, clean, spherical holes in the white matter might be produced in this 
way: the coagulum would most likely be entirely absorbed in process of time, and leave no trace of yellow matter behind it, in consequence of the substance of the brain being uninjured.

In a case which occurred a few days ago, several of these black spherical spots of coagulated blood were observed.

\section{CASE III.}

Richard Clayton, æt. 58: dead twelve hours. About ten days ago he had an apoplectic fit, which was reported to be his second attack : violent delirium came on, and he gradually sank.

On examining his brain, the arachnoid was milky; the membranes almost bloodless: some fluid was found in the membranes and in the ventricles. The dura mater was streaked with fawn-coloured deposit. There were several black, spherical spots of extravasated blood on the surface of the convolutions, in one of crura cerebri, and in various other parts of the cerebrum. The right corpus striatum was softened, with a fawn-coloured hole, and there was one also on the right side of the tuber annulare.

\section{CASE I V.}

Ramollissement; three Cavities resembling old Apoplectic Cysts; Holes in the white Matter.

Thomas Valley, æt. 70. Admitted Sept. 3d, 
having suffered an attack of paralysis, affecting the left arm only, on the preceding day. He was reported to have had no head symptoms previously to this attack, and to be in ordinary health. His forearm became from day to day gradually drawn up, and bent upon the arm, and any attempt to extend the limb occasioned great pain apparently along the course of the nerves. His skin was flabby and presented a dingy or dirty coloured appearance, which I have observed in another instance of ramollissement. He became gradually enfeebled both in body and mind, and a large slough formed on the sacrum. He died Oct. 23d.

Inspection, nine hours after death.-Head. The membranes of the brain were opaque, the opaque parts being thicker in some spots than in others. There was a deposit, almost amounting to cartilage, extending over the longitudinal sinus. The membranes and ventricles contained a very large quantity of fluid. There were three cavities, resembling old apoplectic cysts, containing fluid and some shreds of brown filamentous tissue :-1st. One, very large, occupying a considerable portion of the anterior lobe of the left hemisphere, extending from the surface of the brain to the membrane lining the ventricle; the gray matter appeared eaten away, as if by some insects.-2d. Another cavity was situated near the surface of the posterior lobe of the left hemisphere, and the medullary matter contiguous to it presented numerous small holes, such as have been described as 
the "bread-like appearance."-3d. Another cavity was found in the posterior lobe of the right hemisphere; no other disease was observed in the central parts of the brain. Weight, 2 lbs. 6 oz.

Thorax.-Emphysema of lungs. Heart : partial thinning of the valves of the left ventricle, resembling a small aneurismal pouch, near the aortic valves. Aorta dilated and bony.

Remarks. - In this case we see extensive disease of the brain, probably of considerable duration, without any very marked symptoms, until within a few weeks of death. The atrophy of the brain, and the softening and absorption of the gray matter of the convolutions, connected with the failure of the mental faculties, and the contraction of the fore-arm as a sign of ramollissement, are circumstances of interest in this case.

The absorption of the gray matter of the convolutions, and the holes in the white matter, presenting the appearances of porous bread, may be taken as an evidence of the attempt at curing or arresting the extensive ramollissement which had evidently been going on for a length of time in this man's brain. It is probable that, from the fawn-coloured deposit in the large cavities, extravasation had formerly taken place, and that the ramollissement was connected with these clots. The circumstance of no previous symptoms, or no paralytic symptoms, being noticed in this case,

$$
\text { voL. XIX. }
$$

D D 
may be explained from the fact, that though very extensive, they were at a distance from the central parts of the brain.

$$
\text { CA SE V. }
$$

Cyst from Apoplexy; Holes in the Brain; death from Thoracic Inflammation.

Theophilus Dutallis, æt. 60, about three years ago had an attack of apoplexy, which was attended with paralysis of the right side; the hemiplegia was permanent. He had epistaxis to a large amount, was much reduced, and had several convulsion fits preceding his death.

Inspection, eleven hours after death.-Brain. The arachnoid was thickened, there was considerable effusion on the surface, and a large quantity between some of the convolutions. The septum lucidum was very thin, and the ventricles were distended with fluid. There were numerous holes in different parts of the white matter of the cerebrum, as if portions of the brain had been nicely scooped out; there was one nearly half an inch in diameter over the roof of the left ventricle, and separated from it only by the lining membrane. None of these holes had any trace of the fawn-coloured deposit, nor was there any change of colour in the parts of the brain surrounding them. There were the remains of an old and large clot in the posterior part of the left corpus striatum and thalamus; both these parts of the brain were very 
much shrunk. The cavity was lined by a fawncoloured deposit. The blood-vessels were diseased, but no congestion. Weight, 2 lbs. $10 \mathrm{oz}$.

Thorax.-Heart very large, hypertrophy of left ventricle, valves free. Recent pericarditis, pleuritis, and œdema pulmonem.

Remarks. - In this case we have traces of old and extensive injury of the brain, which appear to have been in a quiescent state, the patient being destroyed by extensive inflammation in another cavity. The remains of the old and large clot in the posterior part of the left corpus striatum and thalamus, account for the hemiplegia of the right side, and it is highly probable that the numerous other cavities without discoloration were traces of ramollissement, coincident with, or consequent upon, and extending around the extravasated clot; or the softening may have occurred at subsequent periods during the three years that intervened between the apoplectic seizure and the death of the patient. The former supposition $I$ think is the most probable.

\section{CASE VI.}

Ramollissement of the Gray Matter cured; Fawncoloured traces of Extravasation on the Arachnoid of Dura Mater.

Richard Bailey, æt. 53, found exposed to the air, and brought to the Infirmary by the police, April 
10th, 1835. He was suffering severe diarrhœea, with symptoms of extreme depression, so as to induce the suspicion of approaching cholera. His skin sallow, with remains of a cutaneous eruption. He has suffered much from privation, and has been discarded by his friends for irregular conduct. He rallied a little, and the diarrhoea abated. His cough continued, and signs of great debility came on, and he died on the 22d.

Dissection, April 22d, 1835. - Head : The arachnoid lining the dura mater laterally, and throughout nearly the whole of the base of the skull, was generally, and more particularly in patches, discoloured by a granular deposit of minute rustycoloured points, evidently the traces of effused blood between the dura mater and the arachnoid. The arachnoid on the right parietal region was separated from the dura mater. Several of the convolutions at the surface of the base of the posterior lobes were in various degrees absorbed, and the fawn-coloured deposit placed there; in one or two places the whole of the gray matter was removed and the white matter exposed, in others an external thin layer only, the arachnoid covering these places was entire. From 8 to $10 \mathrm{oz}$. of serum were effused between the membranes and into the ventricles. The brain was atrophied. The vessels were but little loaded, and had no appearance of disease. Weight, $2 \mathrm{lbs} .7 \mathrm{oz}$.

Thorax. - Fluid in the thmee cavities. Lungs 
emphysematous, and containing tubercles with cavities; extensive.pneumonia in the first stage.

Abdomen.-Lieft kidney lobular and small ; both very hard. Intestines congested with blood.

Remarks.-In this case we observe that the gray matter of the convolutions has been removed, in various degrees, by absorption; in some places completely down to the medullary matter, which, with the fawn-coloured deposit, affords ample evidence of red ramollissement with slight extravasation having previously existed. The man was much reduced by disease and privation, and his brain had partaken in the general atrophy.

This case is also remarkable for the extensive traces of extravasation between the arachnoid and the dura mater, shewn by the rusty or fawn-coloured deposit beneath the former membrane. Layers of extravasated blood in this form, of more recent occurrence, are occasionally met with. I yesterday examined the brain of a man whose previous history was somewhat similar to that of Bailey.

\section{CASE VII.}

Thomas Phipps, æt. 59, was admitted much exhausted from disease of the lungs : he is extremely feeble, with a sallow, dusky skin. Delirium, inco- 
herence, and other signs of a low form of arachnitis soon came on, and he sank on the 6th instant.

On examining his head, twenty-two hours after death, nearly the whole of the arachnoid surface of the dura mater covering the superior part of the hemispheres, was lined by a thin film of coagulated blood, which also extended to some parts of the base of the skull ; in some places it was in patches, and some of the blood had evidently been deposited several days from commencing absorption, and traces of a slight yellow tinge.

In connection with this case, the superficial red ramollissement, with slight extravasation in purpura hæmorrhagica, may be noticed. The following is a good example of this appearance of the brain.

\section{CASE VIII.}

Lawrence Connor; æt. 66, admitted May 19th, 1832, with pneumonia, which was relieved by bleeding, \&c. About a month after his admission, purpura hæmorrhagica appeared on both legs, attended with bleeding from the gums, bloody motions and urine. He lingered for some time, and died emaciated.

On examining his brain, the gray matter of the convolutions of the middle and posterior lobes of the right hemisphere, was covered with a thin, fawn- 
coloured deposit at the inferior and posterior part; the pia mater adhered more firmly in the discoloured parts than on the rest of the surface.

\section{A S E IX.}

Ramollissement of Gray Matter cured; Death from Hamatemesis.

Sarah Giddons, æt. 70. But little was known of her history, except that she died suddenly after vomiting a large quantity of blood.

Inspection, Jan. 17th, 1835, forty-eight hours after death.-Head. The brain was remarkably pale; there was some fluid in the sub-arachnoid tissue. On the inferior surface of the anterior lobes of the cerebrum resting on the orbitar plates of the os frontis, there was a loss of portions of the gray matter, the surrounding parts being of a rusty colour. The same change had taken place at the base of the cerebellum. The dura mater opposed to these softened parts was of the same fawn-colour, and portions of the gray softened matter adhered to it. Weight, 2 lbs. 10 oz.

Stomach.-An ulcer had spread to and exposed two arteries in the stomach, from whence the hæmorrhage came.

Remark.-In this case, though but little is known of the history of the patient, we observe, in the pa- 
thological condition of the brain, traces of previous ramollissement, both in the cerebrum and cerebellum.

\section{CASE X.}

Apoplexy; Hemiplegia; Attacks of Angina Pectoris; Ramollissement of Gray Matter; Traces of Ramollissement in Central Parts; Hypertrophy of the Heart; Ossification of the Coronary Artery.

Thomas Wood, æt. 68, had been under treatment frequently for severe attacks of dyspnœa, sometimes coming on suddenly, and attended with great pain and sense of stricture across the chest; copious bleeding relieved him from many of these attacks. He has latterly suffered several apoplectic seizures, the second of which was attended with hemiplegia of the left side, paralysis of the face, and indistinct articulation. Although the brain now beeame a principal seat of disease, he still had occasional attacks of angina pectoris. His mind became enfeebled, and he shewed indications of childishness. He recovered in some degree the paralysis of the face, and his articulation was occasionally improved, but never perfectly restored. The paralysed lower extremity was much improved both in sensation and motion. The sensation of the arm improved, but the power of moving it was permanently gone. He died exhausted from these repeated attacks.

Inspection, April 13th, 1835, twenty-two hours 
after death.-Head. The brain was extremely white and bloodless. The arachnoid was opaque, and there was some fluid in the sub-arachnoid tissue, and from 4 to $6 \mathrm{oz}$. in the ventricles. The gray matter on the convolutions of both the posterior lobes of the cerebrum was softened to a considerable extent. A cavity lined by a pale membrane was found in the right thalamus. The corpus striatum of the right side was very much diminished in size from previous softening and absorption. There were several small holes in various parts of the cerebrum: the white matter was generally harder and firmer than usual. Weight, 2 lbs. 12 oz.

Thorax.-Pyriform dilatation and hypertrophy of the left ventricle of the heart. Ossification of the coronary artery.

Remarks. - In the brain of this patient, who had several apoplectic attacks, and some of them leaving paralysis, which, though very much lessened in several of the parts affected, became ultimately permanent in the left arm, we find no trace of extravasation of blood ever having taken place. The most accurate observers in this branch of pathology must agree, that where blood is extravasated into the tissue of the brain, however far advanced the clot has been in progress of absorption, there is always a trace of a rusty or fawn-coloured matter left behind; and that this takes place where the cavity has become so far 
contracted that its sides nearly coalesce, and approach to a cicatrix.

This man's death was not occasioned by an apoplectic seizure; he died from general exhaustion, produced by the repeated severe attacks of his two formidable maladies: his brain was found almost bloodless. The recent extensive ramollissement of the gray matter of the convolutions is probably connected with the failure of his mental faculties; this failure may have arisen in part from the general absorption of the brain, and the small holes (traces of previous softening) found in various parts of the brain. The cavity noticed in the right thalamus is most probably the remains of a previously softened state of this part, and accounts for the permanent palsy of the left arm; whilst the wasted state of the right corpus striatum, resulting from ramollissement in it, being checked and relieved, will account for the improving paralysis of the left lower extremity.

This case, with many others which I have observed, verifies the opinions of $M$. Foville, relative to the correspondence of disease in certain parts of the brain with certain paralytic and other symptoms during life.

\section{CASE XI.}

In the case of a man, æt. 60, who died of carditis, and in whom pyriform hypertrophy of the left ven- 
tricle of the heart was discovered, the brain on examination had a stringy texture, and the cut surface of the white matter presented numerous holes like porous bread : there was one the size of a large pea to the left of the median line of the corpus callosum, but not communicating with the ventricle. These may be considered as traces of ramollissement of the white matter having previously existed.

\section{$C A S E \quad X I 1$.}

Copious Effusion with thickened Membranes; Traces of Ramollissement cured; Pneumonia; Hypertrophy of left Ventricle.

Francis Knight, æt. 75, admitted with signs of extensive pneumonia in a very advanced stage, for which no efficient remedies appear to have been used. She soon sank under the disease.

Inspection, thirteen hours after death, May 21. Head.-The membranes of the brain, particularly the arachnoid, were very thick and opaque, and much fluid was found beneath the pia mater, and in the sub-arachnoid tissue. There was also a deposit of thick white matter in various parts, similar to the glandulæ Pacchioni. The blood-vessels on the membranes were very tortuous. The ventricles were very large, and contained from six to eight ounces of fluid. On cutting the white matter to arrive at the lateral ventricles, or making the centrum ovale, as it has been 
termed, it appeared quite granular, apparently from difference of density of the substance. There was a small hole lined by a membrane, in the white matter of the left corpus striatum; in the right corpus striatum there were several holes of various sizes in the gray matter, with lining membranes : there was no trace of fawn-coloured deposit in any of these holes. The blood-vessels were bony and cartilaginous to a considerable extent. Weight, 3 lbs.

Thorax.-Right bronchus very much enlarged. Traces of vivid inflammation in the bronchi. Pneumonia and hepatization in various degrees and stages. The lungs were remarkably black, but no melanotic patches. Heart : hypertrophy of the left ventricle, and dilatation. Other cavities dilated. Aorta ossified.

Remarks.-In this case we have numerous holes lined by a colourless membrane, and containing a colourless fluid in both the corpora striata, which are traces of previous ramollissement. There is also another circumstance worthy of notice, - the granular state, or the difference of density of the white matter on making the horizontal section of the hemispheres. This, I think, has been accounted for on the supposition that the more soft parts have been absorbed in some degree. It is generally allowed that the walls of a cavity, which had contained a clot of blood, may coalesce and adhere. Therefore it is not improbable, that the granular state of the white matter 
may be accounted for by the coalescing and adhesion of some of the numerous small holes which I have described as traces of ramollissement, or of other softened points in the brain; and thus afford further evidence of a more advanced stage, or of the perfect natural cure.

On the preceding facts and observations I make the following inferences.

1. In some of the cases the account of symptoms is necessarily very limited, but this circumstance I do not consider of much importance, as I am desirous of placing the subject on its true basis,-the anatomy of the brain : in other cases, however, we have a sufficiently copious detail of symptoms which indicated the nature of the disease, and the progressive improvement in some of the paralytic sym. ptoms corresponded with the traces of the cure or arrest of ramollissement observed in the brain. The cases, No. II., Mrs. A. S., and No. X., Thomas Wood, are examples in illustration.

2. The traces of the cure of ramollissement of the gray matter are, absorption of one or more layers of this substance on the convolutions, and adhesion of the pia mater to the part; holes in the gray matter of the corpora striata and other central parts, together with atrophy and flattening. When transudation from the blood-vessels, or extravasation, has 


\section{DR. SIMS ON THE CURE OF}

taken place, constituting red ramollissement in the gray matter, a permanent fawn colour of the atrophied convolutions, and of the small holes in the other parts, is observed. The slightest form of this softening of the gray matter is noticed in the case of purpura hæmorrhagica ; in others we have one or more layers removed, or the entire gray matter, leaving the white matter of the hemisphere visible. We sometimes see merely small holes in the corpora striata ; at others, cavities of various sizes and forms, with a marked wasting of these bodies.

3. The traces of the cure of ramollissement in the white matter are, the numerous clean or scooped out holes containing a limpid fluid, some of which are observed to be lined by a fine transparent membrane; others appear as if worm-eaten. These holes are of various sizes and forms, from minute points to the magnitude of a bean : the porous cheese or new bread appearance; the hardened state of the white matter generally in these brains, and particularly in the parts contiguous to the holes; the granular state of the white matter indicating cicatrices; the hardened state of the corpus callosum, fornix, \&c., found in the brains of children and young persons, with fluid in the ventricles, probably the consequence of previous inflammatory ramollissement at an earlier period of life. When there is observed the fawn-coloured deposit in these holes of the white matter, they are traces of red ramollissement of the white matter, or 
probably, in some instances, of what has been sometimes termed capillary apoplexy.

4. I have perhaps to assume in this argument that ramollissement is by some means or other stopped in its progress; and, if this be granted, the preceding detail of the morbid appearances will readily fill up the several steps of the process of cure: the absorption of the softened parts; the adhesion of the pia mater on the surface; the secretion of fluid into the holes; the granular state of the white matter, probably from cicatrization; the hardening of the white matter, probably from effusion of lymph; and the fawn-coloured traces of previous transudation and extravasation. And I think this assumption ought to be granted, from the improvement in the symptoms of some of the patients, corresponding with the state of the brain after death; and because it is consistent with all analogy in the powers by which nature arrests or cures disorganization in other parts of the body.

5. There are some points connected with the subject, as the spherical spots of coagulated blood, the extravasated layer on the arachnoid, the fawncoloured trace of extravasation between the arachnoid and the dura mater, and the connection of the traces of previous ramollissement with apoplectic clots: these are subjects well worthy of attention, but $I$ have sufficiently adverted to. them 
416 DR. SIMS ON RAMOLLISSEMENT OF THE BRAIN. in the remarks on the respective cases in which they occurred.

6. The preceding facts and observations are, I believe, sufficient to attest the cure of ramollissement of the brain, and to set the question at rest on the solid basis of pathological anatomy. 